\title{
PERCEPTION OF MEDICAL STUDENTS TOWARDS ARTIFICIAL BONES AND MODELS OF VISCERA
}

\author{
Dr. Jawid Azizi \\ Lecturer in Anatomy Department \\ Medical Faculty \\ Kabul University of Medical Sciences \\ Kabul, Afghanistan \\ Dr. Saniullah Zalmai \\ Lecturer in Anatomy Department \\ Medical Faculty \\ Kabul University of Medical Sciences \\ Kabul, Afghanistan
}

\author{
Dr. Hidayatullah Danish \\ Lecturer in Anatomy Department \\ Medical Faculty \\ Kabul University of Medical Sciences \\ Kabul, Afghanistan \\ Dr. Enamul haq Moneeb \\ Lecturer in Anatomy Department \\ Medical Faculty \\ Kabul University of Medical Sciences \\ Kabul, Afghanistan
}

\begin{abstract}
Introduction: In learning of anatomy, bones and viscera are very important. Now days, artificial bones are replacing the original bones for study purpose due to unavailability. Original viscera are available for students only at dissection hours. So we have tried to find out perception of medical students towards artificial bones and POP models of viscera.

Objectives: To find out perception of medical students towards artificial bones and viscera and to find out the disadvantages of artificial bone and viscera's models. Materials and Methods: We had prepared a questionnaire consisting of 15 questions, 6 related to bones and 9 related to the POP models of viscera and asked 350 students of 1st and second year medical faculty to answer it.

Result: All the 350 students agreed that bones are necessary for study but only 30 students have bone set (12 original \& 18 artificial). Maximum students get the bones only when made available from department. While 250 (71, 4\%) students said they would prefer original specimen of viscera, over POP models, for studying; but still100 $(28,5 \%)$ wanted to keep the POP models of Viscera while studying its relations from text book.

Conclusion: Good quality artificial bones should be promoted for students, if original bones are not available. It will be better than having nothing. POP models of viscera cannot replace original viscera but due to its handy quality will be helpful for understanding.
\end{abstract}

Keywords: POP Models, Artificial Bones, Medical students.

\section{INTRODUCTION}

For learning of anatomy, bones are very important for medical students. 10- 15 years before every 1 st year medical student had original bone set which were made available by the attendants of the department of anatomy or purchased from the senior students of 2 nd year. But now a day due to legal issues original bones are not easily available even at the cost of 20 to 30 thousand. So, many of the students are using artificial bones. In this study we have attempted to find out how many of the students were using bone set for study and the problems related to the availability of the bone set. For the study of human bones, original or artificial bones are available in market but for the study of viscera no cheap material is available. So we had prepared POP models of human viscera in our department with the help of artist and modeler. For study purpose, these models made available for students in dissection and demonstration hours. In this study, we had tried to find out the perception of students towards these POP models and utility of these models for students.

\section{MATERIALS AND METHOD}

We had prepared a questionnaire consisting of 15 questions, 6 related to bones and 9 related to the POP models of viscera. 350 students of 1 st and 2nd year 2018 batch of Kabul university of medical sciences were involved in the study. Survey was carried at the time of preliminary practical examination of the students as all the students of the batch would be present. Before starting the examination, 5-7 students were sent to a separate room where artificial bones and POP models were shown and discussed with them. Questionnaire was given and asked to solve. After completion of that group, next group of students was called for solving questionnaire. Study was carried for 7 days, 50 students per day.

\section{OBSERVATION AND RESULTS}

Out of 350 students, 16 students left few questions of questionnaire unsolved.

The questionnaire consisted of 6 questions related to availability of bones and acceptance of artificial bones 


\section{International Journal of Engineering Applied Sciences and Technology, 2019 \\ Vol. 4, Issue 7, ISSN No. 2455-2143, Pages 297-300 \\ Published Online November 2019 in IJEAST (http://www.ijeast.com)}

amongst students. Based on the answers opted by the students, following observations and results were drawn below.

\begin{tabular}{|l|l|l|l|l|}
\hline & Best & Good & Average & Bad \\
\hline Originality & 10 & 260 & 40 & 20 \\
\hline Impressions & 110 & 200 & 25 & 5 \\
\hline Size and shape & 105 & 210 & 20 & 10 \\
\hline Quality of Models & 100 & 190 & 40 & 3 \\
\hline Durability & 105 & 185 & 40 & 5 \\
\hline
\end{tabular}

Table 1: Showing the response given by the students for the quality of artificial bones.

Some artificial bones and original bones as shown in Figure 1 was given to students to compare it. Their observation related to quality of artificial bones is shown in table no 1 . Maximum students accepted artificial bones as of good quality. All the 350 students agreed that bones are necessary for study. $250(71.42 \%)$ students referred atlas for studying bones, $80(22.85 \%)$ used text books and only $20(5.71 \%)$ agreed to study the bones with the virtual $3 \mathrm{D}$ images from CD.

Fig.1

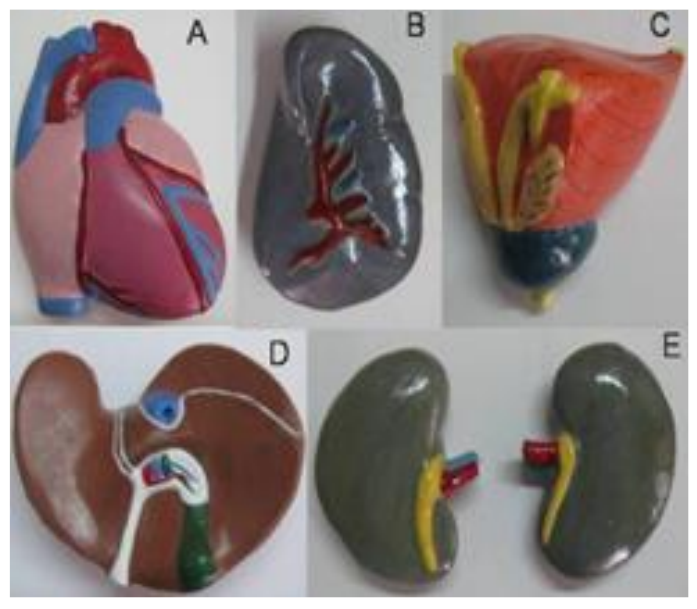

$210(60 \%)$ students said that they would like to keep the bones with them while studying the bones from book. However, only $35(10 \%)$ students had a bone set. Out of these 35 students, 15 had original bone set and 20 had artificial boneset [POP-16; plastic/resin- 06]. When asked about a reason for not having a bone set - $140(40 \%)$ students said that artificial bones that they had seen were not good enough, (22.6\%) students did not know from where to Purchase a bone set, $16(10.6 \%)$ found it to be very costly, $06(4 \%)$ said that no one told them to get it and $03(2 \%)$ thought it was not important for study. Apart from those who have their own bone set , 61(40.6\%) students agreed that they get the original bones only when they get it issued in the dissection hours, $41(27.3 \%)$ said they borrow it from senior students, 15 (10\%) students agreed that they go to museum for studying bones and $16(10.6 \%)$ shared the boneset with batch mates.
Fig.2

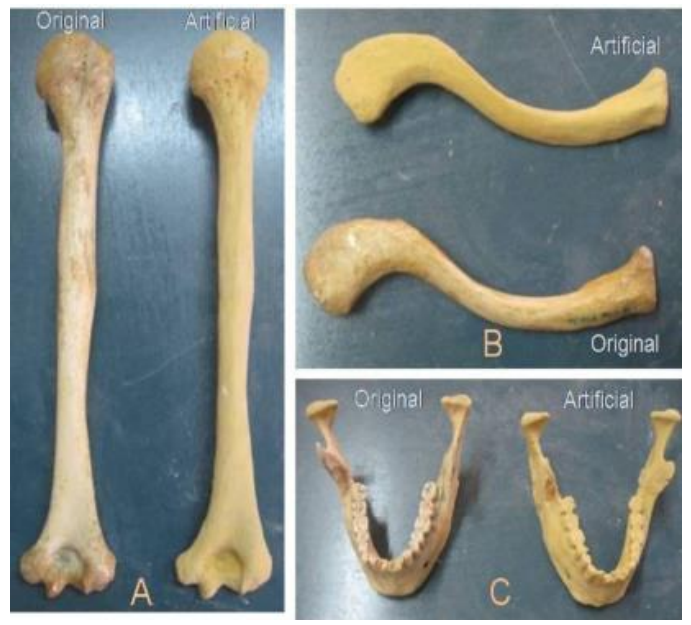

In short it is observed that very few students purchased the bone set and rest of the students manage to study the bones made available Figure 1 shows or from the department. In absence of bones students like to read it from atlas of osteology. The other part of questionnaire included 10 questions related to study of viscera and perception of students towards POP models of viscera. In some of the questions students were allowed to tick multiple options. Following observations were made depending on the options ticked by the students: some POP models of viscera as shown in figure 2 were given to students to examine it. Their observation related to quality of POP models is accepted POP models as of good quality.

Table 2: Showing the response given by the students for the quality of POP Models.

\begin{tabular}{|l|c|c|c|c|}
\hline & Best & Good & Average & Bad \\
\hline Originality & 10 & 260 & 40 & 20 \\
\hline Impressions & 110 & 200 & 25 & 5 \\
\hline Size and shape & 105 & 210 & 20 & 10 \\
\hline Quality of Models & 100 & 190 & 40 & 3 \\
\hline Durability & 105 & 185 & 40 & 5 \\
\hline
\end{tabular}

For studying relationship of viscera 66 (44\%) students said they used textbooks, 62(41\%) agreed to visualize the relations during dissection hours and $22(15 \%)$ used models and specimens in the museum. According to 107 (71.3\%) students, the major difficulty in studying relations of viscera with original specimen was that the viscera were available in dissection hall and museum only. Some 23(15.3\%) students believed that many of the specimens do not have features as mentioned in the textbook. 21(14\%) students observed difficulty in handling the specimen as gloves are not always available and a few 5(3.3\%) did not like to touch the specimen. 16(10.6\%) students made distance from the viscera due to its bad odour.

While $107(71.3 \%)$ students said they would prefer original specimen of viscera, over POP models, for studying; but still $126(84 \%)$ wanted to keep the POP models of viscera while 


\section{International Journal of Engineering Applied Sciences and Technology, 2019 Vol. 4, Issue 7, ISSN No. 2455-2143, Pages 297-300 \\ Published Online November 2019 in IJEAST (http://www.ijeast.com)}

studying its relations from text book. $71(47.3 \%)$ students believed that POP models are good because they can be kept while reading text book at any place and according to 51 (34\%) students special precautions like gloves are not required to handle them. Some 48 (32\%) students found these models helpful for determining the anatomical position and for studying the relations and according to 42 (28\%) maximum features can be visualized as given in the textbook. $27(18 \%)$ students liked POP models as those were helpful in drawing diagrams. However, while discussing demerits of POP models, 57 (38\%) students found the POP models of viscera to be heavier than original specimen and $42(28 \%)$ said that the impressions appeared to be artificially created.

\section{DISCUSSION}

Anatomy forms the base of medical education. Now days, due to unavailability of cadavers and original bones it is difficult for the students to understand only with the 2D diagrams given in the textbooks. Though artificial bones are available in the market, they are not of very good quality. In our survey, 55 students (out of the 114 who did not have a bone set) said that they did not purchase a bone set because the bones were not good enough. In our survey, all the 150 $(100 \%)$ students agreed that bones are necessary for studying osteology. $115(76.6 \%)$ said that they would like to keep the artificial bones, if original bones are not available, while studying from text book. Also 126 (84\%) students agreed that they would prefer to keep viscera models while studying its relations. Therefore, there is a need for the provision of good quality artificial bones and artificial models of viscera. There is some evidence that learning through arts can have a significant impact on students' understanding of the body [1, 2]. So assignments of painting POP models, demonstrating relations can help the students to understand it. But for the purpose they should own the models of viscera. John R. Waters et al. [3] stated that any teaching materials that engage students in activities in which they must interact with the material are worth investigating.

\section{CONCLUSION}

If students have bonesets with them they can mark the attachments of muscles and ligaments and relations of nerves and vessels on them. This can prove to be a better way of memorizing with understanding. B.Kramer and J.T. Soley [4] have performed a survey on medical students and reported that the students apparently experience difficulty with 3D concepts and visualization of structures. Thus, keeping the models of viscera, while studying their relations, may prove to be a better way of clearing the concepts. Some studies have reported dissection as causing extreme anxiety and emotional disturbances in some students [5-7]. Serious concern also arises about health and safety issues for those handling cadaveric material. There can be no such issues with artificial models. Though these models cannot replace the original specimen, they can serve the purpose while studying at home or when cadavers are not available in sufficient numbers. The most important reasons for having no bone set is unavailability of original bones and lack of interest in artificial bones. Good quality artificial bones should be promoted for students, if original bones are not available. It will be better than having nothing. POP models of viscera cannot replace original viscera but due to its handy quality will be helpful for understanding. Required all impressions, structures and marking can be made on the models. These models can also be used during didactic lectures, where we cannot take the original specimen. Students like to use POP models for the study at home.

\section{ACKNOWLEDGMENT}

This research was supported by Anatomy department of Kabul Medical University of Science. We thank our colleagues from the department who provided insight and expertise that greatly assisted the research.

\section{REFERENCES}

[1]. Phillips PS. Running a life drawing class for pre-clinical medical students. Med Educ 2000; 34:1020-5.

[2]. Gull S. Embedding the humanities into medical education. Med Educ 2005; 39:235-6.

[3]. Waters JR, Meter PV, Perrotti W, Drogo S, Cyr RJ. Cat dissection vs. sculpting human structures in clay: an analysis of two approaches to undergraduate human anatomy laboratory education. Adv physiol educ 2005; 29:27-34

[4]. Kramer B, Soley JT. Medical Students Perception of problem Topics in Anatomy. East African Medical Journal 2002;79(8):408-14

[5]. Finkelstein P, Mathers LH. Post-traumatic stress among medical students in the anatomy dissection laboratory.Clin Anat 1990;3(3):219-26.

[6]. Dinsmore CE, Daugherty S, Zeitz HJ. Teaching and learning gross anatomy: dissection, prosection or 'both of the above'? Clin Anat 1999;12:110-4.

[7]. 7.Snelling J, Sahai A, Ellis H. Attitudes of medical and dental students to dissection. Clin Anat 2003;16:165-72

(8). Singh IB. Textbook of Human Osteology. $3^{\text {rd }}$ Edition. New Delhi: Jaypee Brothers Medical Publisher, 2009.

(9). Patil ST, Quadir N, Deopujari R, Gajbhiye V. Perception of medical students towards artificial bones and POP models of viscera. International Journal of Anatomy and Research, 2015; 3(1): 869-72.

(10). McLachlan JC, Bligh J, Bradley P, Searle J. Teaching anatomy without cadavers. Med Educ, 2014; 38:4 18-424.

(11). Bharati S, Deshpande J, Gajbe U, Pandit SV, Jothi SS. Bone set utilization practises by medical students in central 
International Journal of Engineering Applied Sciences and Technology, 2019

Vol. 4, Issue 7, ISSN No. 2455-2143, Pages 297-300

Published Online November 2019 in IJEAST (http://www.ijeast.com)

India. International Journal of Healthcare and Biomedical Research, 2016; 4(3): 103-107.

(12). Turney BW. Anatomy in a Modern Medical Curriculum. Ann R Coll Surg Engl., 2007; 89: 104-107. 